\title{
DIMENSIONAMENTO DO AGRONEGÓCIO NO ESTADO DE MINAS GERAIS ${ }^{1}$
}

\author{
Mamadou Diawara ${ }^{2}$ \\ Marília Fernandes Maciel Gomes ${ }^{3}$ \\ Viviani Silva Lirio $^{3}$ \\ Marielce de Cássia Ribeiro Tosta
}

Resumo - Este estudo objetivou analisar a estrutura econômica de Minas Gerais, mensurar o agronegócio do estado, nos anos de 1980 e 1996, e avaliar a participação deste na constituição do PIB total. Para isso, foram utilizadas matrizes de insumoproduto inter-regionais. Os principais resultados obtidos foram: a) Houve mudança na estrutura do agronegócio nos anos de 1980 e 1996; b) A parcela do Agregado I aumentou, de maneira significativa, a constituição do agronegócio estadual, que passou de 12,31\%, em 1980, para 20,24\%, em 1996; c) Manteve-se relativa estabilidade na evolução do Agregado III, de 1980 a 1996, que passou de $36,40 \%$ para $36,51 \%$; d) Houve queda na participação relativa do Agregado II, que passou de 51,29\%, em 1980, para 43,25\%, em 1996. O estudo mostrou ainda que o Agregado II continua sendo o segmento mais importante do agronegócio mineiro, o que indica que a economia do Estado pode ser classificada como economia alimentar em vias de industrialização. Em relação à participação do agronegócio no PIB, constatou-se que o agronegócio acompanhou a tendência até agora prevalecente no agronegócio do Brasil, ou seja, diminuição gradativa de sua importância no PIB, que passou de 25\%, em 1980, para 20\%, em 1996.

Palavras-chaves - PIB, agronegócio, Minas Gerais.

\footnotetext{
Recebido em 02/03/2005

Aceito em 05/05/2005

2 Doutorando em Administração de Empresa e Marketing - Universidade de Sevilha - diawarama@ hotmail.com

3 Professoras doutoras do Departamento de Economia Rural, Universidade Federal de Viçosa, Viçosa-MG. Email:mfmgomes@ufv.bre vslirio@ufv.br

4 Doutoranda em Economia Aplicada do Departamento de Economia Rural, Universidade Federal de Viçosa, Viçosa-MG. E-mail: marielcetosta@yahoo.com.br.
} 


\section{Introdução}

O modelo de desenvolvimento adotado no Brasil baseou-se no processo de substituição de importações, cujo principal objetivo era a expansão do setor industrial. Nesse modelo de desenvolvimento coube ao setor agrícola evitar crises no abastecimento dos centros urbanos, além de desempenhar importante papel, como fonte de divisas e mercado, para produtos industriais.

A partir da passagem de uma economia agroexportadora para uma industrial, o Brasil apresentou ampla transformação na base produtiva e nas condições de vida da população, com conseqüente aumento de urbanização.

De 1955 a 1995, houve expressiva retração do setor agropecuário, em relação à participação no PIB (Produto Interno Bruto), declínio esse ocupado pelo rápido crescimento da indústria. O setor de serviços, que inclui comércio, transportes, comunicações, instituições financeiras e administração pública, por sua vez, manteve, ao longo do período, participação praticamente constante (Vasconcellos et al., 1999).

De forma análoga à economia brasileira, o desenvolvimento da economia de Minas Gerais foi acompanhado por transformações tanto em suas condições de vida como na base de produção. A economia mineira fundamenta-se em três setores dinâmicos - uma agricultura moderna, um setor industrial amplo e diversificado e um setor de serviços, capaz de oferecer bens competitivos, condições determinantes para o desenvolvimento econômico.

Ademais, a economia mineira ocupa posição de destaque na economia nacional (terceira posição) e apresentou, em 2000, uma taxa de crescimento de 4,2\%, visto que o seu PIB atingiu o valor de 108,5 bilhões de reais (Fundação João Pinheiro - FJP, 2000).

A evolução do PIB do estado mostrou que, nos últimos anos, a economia mineira tem tido bom desempenho. De acordo com dados da Fundação 
João Pinheiro (FJP, 2000), o PIB mineiro, no período de 1985 a 1997 , cresceu a uma taxa média de $2,7 \%$ ao ano. Por um lado, os anos de 1995,1996 e 1997 foram marcados pelos melhores resultados, em razão dos efeitos expansionistas do Plano Real, por outro, os anos de 1998 e 1999, pela desaceleração da economia, não apenas a do estado como a do país, em virtude das crises externas.

O ano de 2000 foi caracterizado pela retomada do crescimento econômico, principalmente a partir do segundo semestre, devido ao desempenho dos setores de comércio, agropecuário, indústria de transformação, extrativa mineral e comunicações, que cresceram 4,9\%, 6\%, 6,1\%, 8,6\% e 14, $4 \%$, respectivamente. Esses setores foram responsáveis por $43,4 \%$ da economia de Minas Gerais, enquanto o da indústria de transformação, por $23,4 \%$ do PIB (FJP, 2000).

A mudança na estrutura produtiva da economia mineira pode ser observada nos dados da Tabela 1, que mostram a variação da participação dos diferentes setores no PIB. Contatam-se queda percentual do PIB agropecuário, em relação ao PIB total do estado, crescimento da parcela de participação dos demais setores até o ano de 1995, e queda na participação do setor de serviços em 2000. Em 1985, o PIB agropecuário, que representava $12,5 \%$ do PIB total do estado, passou para $11,1 \%$ em 1990, 10,7\% em 1995 e 8,51\% em 2000 (Curi, 1997; FJP, 2001). 
Tabela 1 - Participação percentual dos setores da atividade econômica no PIB total do estado de Minas Gerais, em 1985, 1990, 1995 e 2000

\begin{tabular}{|c|c|c|}
\hline Setores & 1985 & 1990 \\
\hline Agropecuário & 12,9 & 11,1 \\
\hline Indústria & 33,8 & 35,2 \\
\hline Serviços & 53,3 & 53,7 \\
\hline PIB total & 100,0 & 100,0 \\
\hline
\end{tabular}

Fonte: Curi (1997) e FJP (2001).

Em se tratando especificamente da agropecuária mineira, verifica-se que, na década de 80 , as culturas agrícolas voltadas para a exportação, como café, soja e açúcar, foram beneficiadas pela política econômica que visava à superação das restrições externas e ao reaquecimento das economias centrais. No entanto, a pecuária não apresentou desempenho satisfatório, em razão da queda dos preços externos da carne, do tabelamento dos preços do leite, do fim dos estímulos governamentais às exportações e da insuficiência da renda dos consumidores.

A desaceleração do crescimento da economia nacional, na década de 80 , gerou a retração da capacidade de investimento do setor público e a abertura indiscriminada ao resto do mundo na década de 90 , fatos que afetaram a economia mineira, principalmente no que diz respeito à agropecuária.

A abertura comercial da economia tem ampliado o grau de exposição dos produtos nacionais e, consequientemente, dos produtos mineiros à concorrência internacional, provocando uma reestruturação no sistema produtivo. Para ajustar-se a esses novos padrões, têm-se buscado melhoria dos padrões de eficiência e produtividade, controle de qualidade, treinamento da mão-de-obra, racionalização das linhas de produção, modernização tecnológica e introdução de novas técnicas de gestão e 
Mamadou Diawara,Marília Fernandes Maciel Gomes,

Viviani Silva Lirio \& Marielce de Cássia Ribeiro Tosta

administração. De forma geral, as grandes mudanças foram introduzidas nas indústrias de transformação ${ }^{5}$, na extrativa mineral e na agropecuária.

De acordo com Tollini (1999), essa reestruturação do sistema produtivo agropecuário foi um dos principais motivos da redução da participação do setor agropecuário no cômputo do PIB do estado, uma vez que esse setor não perdeu importância na economia mineira, mas passou a contabilizar, fora do setor primário, tarefas que antes eram executadas nas próprias fazendas, como beneficiamento e armazenamento. Além disso, o setor agropecuário dinamizou-se e integrou-se profundamente à indústria, criando múltiplas relações tecnológicas, produtivas, financeiras e de negócios com as demais atividades da economia (Furtuoso et al., 1998).

Dessa forma, não é conveniente analisar a agropecuária somente pelo enfoque anteriormente discutido, ou seja, pela ótica dos setores de produção. Assim, o conceito analítico de Complexo Agroindustrial (CAI) afigura-se como unidade de análise adequada para estudar a dinâmica da agropecuária, considerando-se as múltiplas relações do setor rural com a indústria e com os correspondentes mercados.

No entanto, análises dessa magnitude envolvem grupos econômicos atrelados ao setor agropecuário. Ao conjunto de atividades econômicas, que abrangem empresas que oferecem produtos e serviços à agropecuária, dá-se o nome de indústria para a agricultura, que é composta do setor a montante, ou seja, de empresas que se incumbem da produção de bens de capital e de insumos industriais para o setor rural. Da mesma forma, os grupos que adquirem da agropecuária suas matérias-primas são denominados de agroindústria e constituem a cadeia prospectiva da agropecuária, ou seja, o setor a jusante.

Diversos trabalhos têm sido realizados com o intuito de mensurar a participação e a evolução do PIB do CAI no Brasil, entre eles, os de Furtuoso et al. (1998), Furtuoso e Guilhoto (2000), Montoya e Guilhoto

Inclui produtos alimentares, metalurgia e material de transporte. 
(2000) e Finamore e Montoya (2001). No entanto, o que se constatou é que para o estado de Minas Gerais, em específico, nenhum trabalho foi realizado com o objetivo de dimensionar o agronegócio, razão de ser relevante a análise deste.

Em face da diversificação e consolidação da base produtiva de Minas Gerais e da importância da agropecuária e dos setores com ela relacionados e, especialmente, das transformações por que vêm passando nos últimos anos, pretendeu-se, neste trabalho, analisar o desempenho do agronegócio mineiro, com vistas em identificar as principais mudanças estruturais e os mecanismos de ajustes ocorridos. Especificamente, pretendeu-se caracterizar a estrutura produtiva de Minas Gerais, analisar a evolução da estrutura do agronegócio mineiro, por meio do Agregado I (que se refere às indústrias produtoras de bens e insumos para a agricultura), do Agregado II (que engloba todas as atividades de produção) e do Agregado III (que inclui todas as atividades de processamento e comercialização de bens agrícolas) e avaliar o agronegócio mineiro e a evolução de sua participação no PIB do Estado.

\section{Metodologia}

Vários trabalhos visaram estudar o agronegócio do Brasil e de algumas regiões, entre os quais se destacam os de Moretto (2000), Paré (2000) e Rodrigues et al. (2000). Nestes estudos, a análise do agronegócio partiu de uma abordagem sistêmica, mediante uso de matrizes de insumoproduto, por considerar uma integração entre os fluxos de insumo e produto entre setores. Os trabalhos de Davis e Goldberg (1957) e Malassis (1969) serviram como referencial teórico para esses estudos. Neste trabalho, à luz dos demais estudos, adotou-se o mesmo referencial teórico.

O modelo de insumo-produto, desenvolvido por Leontief, fornece informações sobre vários setores da economia, o que permite uma descrição ampla do sistema econômico a partir dos setores fornecedores de insumos e fatores de produção para as propriedades rurais, ou seja, 
dos setores a montante ou agregado I, do próprio setor de produção, que representa o agregado II, além dos setores que recebem a produção agropecuária para agregar valor mediante armazenamento, processamento e distribuição para o consumidor final e que também podem ser denominados de setores a jusante da produção ou, simplesmente, agregado III.

Neste trabalho, a mensuração da dimensão do Agregado I é realizada por meio do uso das tabelas de insumo-produto referentes aos valores dos insumos adquiridos pelo setor agropecuário, por não se dispor de dados referentes ao valor adicionado das indústrias fornecedoras de insumos para a agropecuária. Para isso, calculou-se, indiretamente, o valor do Agregado I, utilizando os componentes do consumo intermediário do setor agropecuário. A principal hipótese subjacente a essa sistemática de cálculo é que, segundo Furtuoso (1998), os setores industriais fornecedores de bens de capital e de insumos para a agropecuária apresentam um consumo intermediário de produtos agrícolas praticamente nulo.

A partir dessa suposição, o valor do Agregado I foi calculado da seguinte forma:

Agregado $\mathrm{I}=Z_{11}+Z_{21}+\ldots \ldots . .+Z_{161}+M_{i}^{R}+M_{i}^{X}$,

em que $i=1,2,3, \cdots, 16$ setores. Os 16 setores são definidos pela desagregação da matriz de insumo-produto da economia mineira. Essa desagregação é composta pelos setores relacionados a seguir: (1) Agropecuária; (2) Mineração; (3) Minerais não-metálicos; (4) Metalurgia e mecânica; (5) Material elétrico; (6) Agroindústrias; (7) Celulose, papel e gráfica; (8) Borracha; (9) Química; (10) Farmacêutica e perfumaria; (11) Plásticos; (12) Indústrias diversas; (13) Energia, saneamento e comunicações; (14) Construção civil; (15) Transporte e comércio; (16) Serviços; $Z_{1}$ até $Z_{16}$ representam os insumos consumidos pelo setor agropecuário, originados em Minas Gerais; e $M_{i}{ }^{K} \operatorname{com~} \mathrm{K}=\mathrm{R}, \mathrm{X}$ 
representam as compras (importações) de insumos feitas pelo setor agropecuário do resto do Brasil (MR) e do exterior (Mx).

Em razão disso, o valor do Agregado I pode se apresentar superestimado, pelo fato de ser estimado indiretamente a partir do valor dos insumos consumidos pelo setor agropecuário, e não pelo valor agregado do setor agropecuário em si.

Para dimensionar o Agregado II (setor agropecuário), foi considerada a renda ou o valor adicionado gerado por este setor, incluindo o setor de extração vegetal, ou seja,

Agregado II $=\mathrm{VA}_{1}$,

em que VA é valor adicionado a preços básicos, gerado pelo setor agropecuário.

O Agregado III (a jusante da produção), por sua vez, foi dividido em duas partes - produção agroindustrial (PAI) e distribuição final (DIF), o que requer duas etapas de cálculo.

Em primeiro lugar, foi calculado o valor da produção industrial, cuja referência foi o valor adicionado gerado pelas indústrias de bases agrícolas que compõem o setor agroindustrial de Minas Gerais.

Neste trabalho foram adotados os critérios da Classificação Industrial Internacional Uniforme (CIIU - versão II) do conjunto das atividades econômicas, que divide o setor agroindustrial em: 1) Serrarias e fabricação de artigos de madeira e mobiliário; 2) Indústria têxtil; 3) Artigos de vestuário e acessórios; 4) Fabricação de calçados e artigos de couro e peles; 5) Produtos de café; 6) Beneficiamento de produtos de origem vegetal, inclusive fumo; 7) Abate e preparação de carnes; 8) Resfriamento e preparação de leite e laticínios; 9) Fábrica de açúcar; 10) Fabricação de refino de óleo vegetal e de gorduras para alimentação; e 11) Fabricação de produtos alimentícios e bebidas. 
Mamadou Diawara,Marília Fernandes Maciel Gomes,

Viviani Silva Lirio \& Marielce de Cássia Ribeiro Tosta

No dimensionamento dos Agregados I, II e III usou-se uma versão modificada do modelo adotado por PARRÉ (2000), ao analisar o agronegócio no Paraná. No presente trabalho, utilizaram-se, na análise, preços básicos em vez de preços a custos de fatores, por não se dispor de dados sobre impostos indiretos. O preço a custo de fator é o preço básico menos os impostos indiretos sobre a atividade.

Assim, o valor da produção agroindustrial (PAI) de Minas Gerais foi obtido pela seguinte equação:

$\mathrm{PAI}=\mathrm{VA}_{6}$,

em que $\mathrm{VA}_{6}$ representa o valor adicionado a preços básicos, gerado pelo setor agroindustrial. Por último, foi calculado o valor da distribuição final (DIF) do agronegócio mineiro, para o qual se considerou, para esse fim, o valor agregado dos setores relativos a "transporte e comércio" e "serviços".

Tendo em vista que no valor adicionado dos dois setores são incluídos todos os produtos do sistema econômico do Estado, é necessário que se faça uma ponderação para destinar ao agronegócio, exclusivamente, a parcela que corresponde à participação dos produtos agropecuários e produtos agroindustriais na demanda final de produtos do Estado.

Dessa forma, no estabelecimento do valor da distribuição final (DIF) deve-se considerar o cálculo da Produção Interna (PI) do Estado.

$\mathrm{PI}=\mathrm{DFGP}-\mathrm{TPI}$,

em que DFGP é demanda final global de produtos de Minas Gerais e TPI, valor total dos produtos importados para a demanda final de Minas Gerais, oriundos do resto do Brasil e do exterior.

A segunda etapa constitui-se do cálculo da margem de comercialização (MC) ou do total da distribuição de Minas Gerais. 
$\mathrm{MC}=\mathrm{VA}_{15}+\mathrm{VA}_{16}$,

em que $\mathrm{VA}_{15}$ é valor adicionado a preços básico, gerado pelo setor de transporte e comércio; e $\mathrm{VA}_{16}$, valor adicionado a preços básicos, gerado pelo setor de serviços.

A estimativa da demanda final de produtos agropecuários (DFPA) e da demanda final de produtos do setor agroindustrial (DFPAI), de Minas Gerais, é obtida por meio das expressões (3) e (4).

$$
\begin{aligned}
& D F P A=\mathrm{Y}_{1}^{1}+\mathrm{Y}_{1}^{\mathrm{XE}}+\mathrm{Y}_{1}^{\mathrm{XR}}+\mathrm{Y}_{1}^{\mathrm{CG}}+\mathrm{Y}_{1}^{\mathrm{CF}} . \\
& \text { DFPA } \mathrm{I}=\mathrm{Y}_{7}^{1}+\mathrm{Y}_{7}^{\mathrm{XE}}+\mathrm{Y}_{7}^{\mathrm{XR}}+\mathrm{Y}_{7}^{\mathrm{CF}}+\mathrm{Y}_{7}^{\mathrm{CF}} .
\end{aligned}
$$

Em seguida, foi estimado o valor da distribuição final (DIF), correspondente às atividades dos setores agropecuário e agroindustrial de Minas.

$\mathrm{DIF}=((\mathrm{DFPA}+\mathrm{DFPAI}) / \mathrm{PI}) * \mathrm{MC}$.

Somado o valor da produção agroindustrial (PAI) com o valor da distribuição final (DIF), encontra-se o total do Agregado III.

Agregado III = PAI + DIF,

em que PAI é valor da produção de Minas Gerais e DFI, valor da distribuição final da agropecuária e agroindústria de Minas Gerais.

A dimensão do agronegócio do Estado de Minas Gerais pode ser obtida pela soma das expressões (1), (2) e (9), ou seja, agronegócio = Agregado I + Agregado II + Agregado III.

Os dados utilizados neste trabalho são provenientes de duas matrizes de insumo-produto. A primeira, referente ao ano de 1980, foi elaborada por 
Mamadou Diawara,Marília Fernandes Maciel Gomes,

Viviani Silva Lirio \& Marielce de Cássia Ribeiro Tosta

uma equipe de consultores contratada pelo $\mathrm{BDMG}^{6}$, publicada em 1991, e a segunda, de 1996, foi também elaborada pelo BDMG (2001). Essas matrizes foram desenvolvidas com base na metodologia proposta por Leontief e agregadas em 16 setores, com o intuito de simplificar o dimensionamento do agronegócio.

\section{Análise dos resultados}

A análise dos resultados é composta de duas partes. Na primeira, apresenta-se a estrutura produtiva de Minas Gerais nos anos de 1980 e 1996, por meio dos indicadores econômicos escolhidos (Valor AdicionadoVA, Demanda Final-DF, Importações e Valor Bruto da Produção-VBP). Na segunda, discutem-se a evolução do agronegócio do estado de Minas Gerais e a participação deste no PIB mineiro.

A análise do conjunto desses indicadores, para os 16 setores em estudo, mostra que a economia mineira apresentou tendências diferentes, no período analisado, com alterações na sua estrutura. Em relação à DF, nota-se que seu valor atingiu CR $\$ 1.351 .162$ milhão, em 1980, e 48.441milhões, em 1996, enquanto o VA, a soma de todos os setores, correspondeu a CR \$1.105.186 milhão, em 1980, e $\mathrm{R} \$ 71.771$ milhões, em 1996. Já em relação ao VBP, os dados da pesquisa mostram que seu valor total atingiu CR \$2.179.769 milhões, em 1980, e R \$ 1.215 milhão, em 1996, enquanto as importações totais do Estado de Minas Gerais atingiram o patamar de CR \$ de 203.209 milhões, em 1980, e R \$ 3.530 milhões, em 1996.

A participação do valor bruto de produção da agropecuária na economia aumentou 12\%, nos anos de 1980 e 1996, enquanto no setor agroindustrial houve queda de 11,5\%, em 1980, para 8,1\%, em 1996 (Tabela 1).

As atividades mais expressivas na composição do setor agroindustrial, em relação ao valor bruto da produção, foram, em 1980, Resfriamento e

\footnotetext{
6 Elaborada pelos professores José Afonso Bicalho Beltrão da Silva e Ronaldo Lamounier Locatelli.
} 
Preparação de Leite e Laticínios, 21,98\%, seguida de Indústria Têxtil (19,30\%), Abate e Preparação de Carnes (19,20\%), Indústria de Café $(9,47 \%)$ e Beneficiamento de Produtos de Origem Vegetal $(9,11 \%)$. Em 1996, destacaram-se as atividades de Abate e Preparação de Carnes (21,24\%), Fabricação e Refino de Óleos Vegetais e de Gorduras para Alimentação (19,17\%), Indústria de Café (15,52\%), Indústria de Açúcar $(9,67 \%)$ e Beneficiamento de Produtos de Origem Vegetal, inclusive Fumo $(8,82 \%)$ (Tabela 2).

A queda da participação no valor bruto da produção das agroindústrias deve-se, em grande parte, à redução drástica de seus componentes, que apresentaram maiores pesos na sua composição, principalmente os gêneros Resfriamento e Preparação de Leite e Laticínios e Indústria Têxtil, cujas participações passaram, respectivamente, de $21,98 \%$ e 19,20\%, em 1980, para 0,09\% e 8,5\%, em 1996. A participação do setor de abate do gênero Abate e Preparação de Carnes, importante segmento na composição do valor bruto da produção do setor de agroindústrias, foi crescente, apesar de seu crescimento não ter sido suficiente para compensar as perdas dos dois primeiros segmentos.

Os setores que se destacaram na economia mineira em 1980, por apresentarem maior valor da produção, além dos setores da agropecuária e o agroindustrial, foram: Serviços, responsável por $24,1 \%$ do valor total da produção; Metalurgia e Mecânica, 17,4\%; Transporte e Comércio, 13,6\%. Em 1996, por sua vez, destacaram-se Serviços, 26,7\%; Metalurgia e Mecânica, 16,8\%; Construção Civil, 12,5\%; Transporte e Comércio, $11,6 \%$. 
Tabela 1 - Estrutura produtiva dos 16 setores de Minas Gerais, nos anos de 1980 e 1996, em relações percentuais

\begin{tabular}{|c|c|c|c|c|c|c|c|c|c|}
\hline \multirow[t]{2}{*}{ Código } & \multirow[t]{2}{*}{ Setores - Descrição } & \multicolumn{2}{|c|}{ VBP } & \multicolumn{2}{|c|}{ VA } & \multicolumn{2}{|c|}{ DF } & \multicolumn{2}{|c|}{ Importações } \\
\hline & & 1980 & 1996 & 1980 & 1996 & 1980 & 1996 & 1980 & 1996 \\
\hline 01 & Agropecuária & 8,9 & 9,3 & 14,1 & 9,1 & 5,4 & 2,3 & 2,2 & 4,2 \\
\hline 02 & Mineração & 3,3 & 1,5 & 4,9 & 1,5 & 4,3 & 0,8 & 0,7 & 0,7 \\
\hline 03 & Minerais Não-Metálicos & 3,0 & 2,0 & 2,6 & 2,2 & 1,7 & 0,1 & 1,7 & 0,8 \\
\hline 04 & Metalurgia e Mecânica & 17,4 & 16,8 & 9,3 & 10,2 & 13,5 & 8,4 & 19,4 & 42,1 \\
\hline 05 & Fabric. de Apar. e Equipam de Mate rial Elétrico & 0,5 & 0,6 & 0,5 & 0,2 & 0,5 & 0,1 & 0,9 & 1,3 \\
\hline 06 & Agroindústrias & 11,5 & 8,1 & 6,9 & 5,3 & 13,8 & 4,0 & 10,9 & 5,5 \\
\hline 07 & Celulose, Papel e Gráfica & 1,0 & 0,9 & 1,3 & 0,5 & 0,8 & 0,0 & 1,2 & 1,4 \\
\hline 08 & Borracha & 0,1 & 0,1 & 0,1 & 0,1 & 0,0 & 0,0 & 0,6 & 0,3 \\
\hline 09 & Química & 3,8 & 3,7 & 2,1 & 2,3 & 1,2 & 0,8 & 22,8 & 11,5 \\
\hline 10 & Farmácia e Perfumaria & 0,1 & 0,3 & 0,1 & 0,3 & 0,1 & 0,2 & 0,2 & 0,9 \\
\hline 11 & Plásticos & 0,2 & 0,1 & 0,1 & 0,1 & 0,1 & 0,0 & 0,3 & 0,1 \\
\hline 12 & Indústrias Diversas & 1,0 & 0,9 & 1,0 & 0,9 & 1,3 & 0,4 & 1,3 & 0,7 \\
\hline 13 & Energia, Saneamento e Comunicação & 3,0 & 4,9 & 5,0 & 6,2 & 2,6 & 5,5 & 0,7 & 4,4 \\
\hline 14 & Construção Civil & 8,4 & 12,5 & 6,6 & 12,5 & 11,6 & 21,4 & 10,7 & 7,1 \\
\hline 15 & Transporte e Comércio & 13,6 & 11,6 & 13,7 & 13,6 & 13,4 & 12,9 & 9,1 & 9,7 \\
\hline 16 & Serviços & 24,1 & 26,7 & 31,7 & 35,1 & 29,9 & 43,0 & 17,3 & 9,0 \\
\hline & Total & 100.0 & 100,0 & 100,0 & 100,0 & 100,0 & 100,0 & 100,0 & 100,0 \\
\hline
\end{tabular}

Fonte: Resultados da pesquisa.

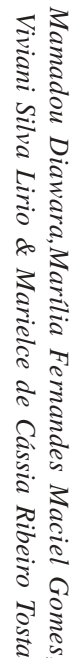


Tabela 2 - Estrutura produtiva de Minas Gerais das atividades que compõem o setor agroindustrial, nos anos de 1980 e 1996, em relações percentuais



Fonte: Resultados da pesquisa. 
Quanto ao valor adicionado, os setores de Serviços, Agropecuária, Transporte e Comércio, Metalurgia e Mecânica e Agroindústrias apareceram como os mais dinâmicos em 1980, dada uma participação de $31,7 \%, 14,1 \%$ 13,7\% e 9,3\% e 6,9\%, respectivamente (Tabela 1). Em 1996, os setores de Serviços, Transporte, Comércio, Construção Civil, Metalurgia e Mecânica e Agropecuária foram os mais expressivos, visto que contribuíram, respectivamente, com $35,1 \%, 13,6 \%, 12,5 \% 10,2 \%$ e $9,1 \%$ para o valor adicionado.

O setor agroindustrial, de modo geral, registrou queda no valor adicionado, que passou de 6,9\%, em 1980, para 5,3\%, em 1996 (Tabela 1). Apesar disso, destacaram em 1980 os setores da Indústria Têxtil, Abate e Preparação de Carnes, Beneficiamento de Produtos de Origem Vegetal, inclusive Fumo, Resfriamento e Preparação de Leite e Laticínios e Indústria de Café. Em 1996, destacaram-se os setores de Beneficiamento de Produtos de Origem Vegetal, inclusive Fumo, Abate e Preparação de Carnes, Outras Indústrias Alimentares e de Bebidas, Fabricação e Refino de Óleos Vegetais e Gorduras e Indústria do Café (Tabela 2).

Quanto à demanda final, observa-se que o setor de Serviços foi o mais relevante em sua formação em 1980, em termos de participação na economia mineira, com participação relativa de quase 29,9\%. Em seguida, destacam-se os setores Agroindustrial (13,8\%), Metalurgia e Mecânica (13,5\%), Transporte e Comércio (13,4\%) e Construção Civil (11,6\%). De modo similar a 1980, o setor de Serviços foi, em 1996, o que apresentou maior participação na Demanda Final (43\%), seguido de Construção Civil (21,4\%), Transporte e Comércio (12,9\%) e Metalurgia e Mecânica $(8,4 \%)$ (Tabela 1$)$.

A participação do setor da Agropecuária na demanda final decresceu de 5,4\% para 2,3\%, de 1980 a 1996, respectivamente. O setor da agroindústria, de forma análoga ao de Agropecuária, apresentou perda de participação, que passou de 13,8\%, em 1980, para 4\%, em 1996 (Tabela 1). 
Ressalta-se que as atividades de Resfriamento e Preparação de Leite e Laticínios, Abate e Preparação de Carnes, Indústria Têxtil, Indústria do Café e de Beneficiamento de Produtos de Origem Animal, inclusive Fumo, foram as que mais determinaram a composição do valor de 1980, visto que participaram com 23,10\%, 22,77\%, 13,5\%, 11,47\% e 10,56\%, respectivamente. Já em 1996, as atividades de Abate e Preparação de Carnes, Indústria do Café, Fabricação de Refino de Óleos Vegetais e de Gorduras, Indústria de Açúcar e de Beneficiamento de Produtos de Origem Animal, inclusive Fumo, foram as que apresentaram maior participação na composição da demanda final do setor de Agroindústrias, com 30,66\%, $22,30 \%, 20,01 \%, 11,21 \%$ e $7,12 \%$, respectivamente (Tabela 2).

Os setores que mais se destacaram na economia mineira, em relação à importação, em 1980, foram o Químico, com 22,6\% do total das importações; Metalurgia e Mecânica, 19,4\%; Serviços, 17,3\%; e Agroindústrias, $10,9 \%$. Os setores com menor participação nas importações totais foram os de Farmácia e Perfumaria e de Plásticos. Em 1996, os maiores índices de importação ficaram com os setores de Metalurgia e Mecânica, com 42,1\% do valor total das importações, seguidos dos de Química, 11,5\%, Transporte e Comércio, 9,7\%, Serviços, 9\%, e Construção Civil, 7,1\% (Tabela 1).

Com relação ao setor agroindustrial, constata-se tendência de declínio nas importações do Estado, as quais passaram de 10,9\%, em 1980, para $5,5 \%$, em 1996 (Tabela 1). Na pauta das importações, em 1980, os produtos e serviços ligados às atividades de Serrarias e Fabricação de Madeira e Mobiliário, Indústria Têxtil, Fabricação de Artigos de Vestuários e Acessórios, Fabricação de Calçados e de Artigos de Couro e Peles e Indústria do Café foram os mais expressivos, visto que contribuíram, respectivamente, com 32,89\%, 28,07\%, 17,32\%, 6,54\% e 5,18\%. Por outro lado, em 1996, as atividades de Indústria Têxtil, Fabricação e Refino de Óleos Vegetais e de Gorduras, Outras Indústrias Alimentares, Fabricação de Calçados e Artigos de Couro e Peles e Indústria de Açúcar lideraram o ranking das importações, com 35,16\%, 25,33\%, 8,72\%, 6,96\% e $6,61 \%$, respectivamente (Tabela 2 ). 
De modo geral, os resultados encontrados neste estudo corroboram a tese de que a abertura comercial, intensificada no início da década de 90 , teve impacto direto na composição setorial da economia mineira. No que se refere às importações, observa-se que estas afetaram, de forma significativa, a produção mineira.

No ano de 1996, o segundo período de análise, pode-se verificar que o setor de metalurgia e mecânica, de modo similar a outros da economia mineira, foi influenciado tanto pelos efeitos da abertura comercial quanto pela implementação do Plano Real (1994). Esse setor representou 42,1\% das importações e foi o mais afetado por tais políticas, em razão de ele ter sido, ao longo do tempo, protegido da competição externa por elevadas tarifas de importação. Com a redução dessa proteção e da valorização da moeda Real, no período pós-Plano Real, houve um favorecimento ao crescimento das importações e à aquisição de tecnologias pelo setor.

Além do setor de metalurgia e mecânica, o setor de madeira e mobiliário também foi afetado pela abertura comercial, dado que o aumento de suas exportações e a retração das importações não foram suficientes para contrapor à redução da demanda doméstica.

O setor da indústria têxtil, de modo similar ao de metalurgia e mecânica, apresentou elevação no seu coeficiente de importação, que passou de 28,07\%, em 1980, para 35,16\%, em 1996. Esse comportamento foi acompanhado pela retração da participação desse setor no VBP, VA e DF, resultado que se justifica pelo fato de Minas Gerais ter sua produção voltada para produtos que utilizam o fio de algodão em seu processo produtivo e ter como principal fornecedor dessa matéria-prima a região Centro-Oeste brasileira, resultando, assim, em maior custo de produção. Além disso, constata-se aumento significativo da produção de produtos têxteis com uso de fibras sintéticas em todo o país, tendência que não foi observada em Minas Gerais. Por último, tem-se o baixo peso relativo do setor de confecções no setor da indústria têxtil em Minas Gerais, que possui pequena participação no VA, em comparação ao estado de São Paulo e Brasil. 
Quanto ao setor de fabricação e refino de óleos vegetais e de gordura para alimentação, constata-se elevado crescimento do VBP, VA, DF e das importações, comportamento que está associado à entrada de novas empresas no triângulo mineiro, as quais ampliaram a capacidade de processamento da matéria-prima originária do próprio Estado, bem como de outros estados, especialmente do Centro-Oeste brasileiro. Este é um setor que continua crescendo a elevadas taxas anuais em Minas Gerais.

Na Tabela 3, são apresentadas a estrutura e a dimensão do agronegócio no estado de Minas Gerais, de 1980 e 1996.

Tabela 3 - Estrutura do agronegócio, em valores percentuais, no estado de Minas Gerais, nos anos de 1980 e 1996

\begin{tabular}{cccccc}
\hline \multirow{2}{*}{ Anos } & & \multirow{2}{*}{ Agregado I } & Agregado II & \multicolumn{2}{r}{ Agregado } \\
\cline { 5 - 6 } & & & & PAI & DIF \\
\hline 1980 & $\%$ & 12,31 & 51,29 & 25,17 & 11,23 \\
1996 & $\%$ & 20,24 & 43,24 & 25,22 & 11,30 \\
\hline
\end{tabular}

Fonte: Resultados da pesquisa.

No agronegócio em Minas Gerais, os componentes do Agregado I, II e III (DIF e PAI) apresentaram comportamento diferenciado nos dois períodos analisados. Ademais, constatou-se que, do valor total do agronegócio em 1980, 12,31\% representam o Agregado I; 51,29\%, o Agregado II; e 36,40\%, o Agregado III, e 11,23\% é constituído pela DIF e 25,77\%, pelo PAI. Em 1996, a parcela do Agregado I no valor total do agronegócio foi de 20,24\%, a do Agregado II, 43,24\%; e a do Agregado III, 36,51\%, sendo $11,30 \%$ proveniente do PAI e $25,22 \%$, da DIF.

Esses resultados mostraram aumento da participação do Agregado I, queda da participação do Agregado II e participação estável do Agregado III no agronegócio mineiro. 
Em relação ao comportamento geral dos Agregados I e II, ou seja, aumento do Agregado I e redução do Agregado II, observa-se que coincide com as tendências do agronegócio brasileiro apresentadas por Furtuoso (1998), nos anos de 1980, 1985 e 1990.

A razão da boa evolução do Agregado I tem origem no processo de modernização da agricultura, ocorrida principalmente nos anos 70 , durante a qual as indústrias fornecedoras de insumo para a agropecuária se fortaleceram. $\mathrm{O}$ crédito rural foi um dos principais elementos da modernização, já que, por meio do Sistema Nacional de Crédito Rural, possibilitou aumento de recursos para compra de fertilizantes, defensivos agrícolas, máquinas e tratores para agropecuária.

A queda da participação do Agregado II pode estar ligada à estrutura dos mercados do agronegócio, onde a agricultura vem sendo pressionada por segmentos mais bem articulados e com estruturas econômicas oligopolistas e monopolistas. Além disso, é importante reconhecer que a forte dependência da produção agrícola do Estado por certos produtos tradicionais, como café, cana-de-açúcar e outros, também poderia estar por trás da queda do valor do Agregado II, uma vez que os produtos comercializados in natura estão perdendo valor no mercado em relação a outros com maior valor agregado, ou seja, produtos processados.

Apesar da queda da participação do Agregado II, o segmento ainda é o mais dinâmico do agronegócio mineiro. Segundo Malassis (1969), quando isso ocorre, é sinal de que a economia agroindustrial se encontra num estágio industrial pouco desenvolvido. Além disso, percebe-se que o Estado apresenta pouco desenvolvimento do setor a jusante, ao contrário do que vem ocorrendo no agronegócio brasileiro e em alguns Estados, como o Paraná, no qual o segmento que participou mais intensamente na composição do agronegócio, nos últimos anos, foi o Agregado III.

A particularidade deste estudo em relação aos anteriores, sobre tendências do agronegócio, reside no comportamento diferente do Agregado III, uma vez que este ficou praticamente estável, perdendo importância na participação em relação ao Agregado I, diferentemente do que vem 
ocorrendo no Brasil. Esperava-se maior participação desse segmento no valor total do agronegócio, visto que é neste componente da cadeia que se agrega mais valor ao produto agrícola, gerando, conseqüentemente, mais renda para o agronegócio.

A explicação para esse comportamento do Agregado III estaria no baixo nível de processamento do produto agropecuário dentro do próprio Estado, o qual ainda se destaca como grande fornecedor de produtos primários e constitui apenas um elo da cadeia.

A participação dos Agregados I e III na estrutura do agronegócio, quanto ao total comercializado para os consumidores, aumentou, visto que passou de 48,71\% (1980) para 56,75\% (1996), participação oriunda do setor urbano (setores a montante e a jusante da produção), enquanto a participação originária do campo (produto dos produtores agrícolas) caiu, passou de $51,29 \%$ para $43,24 \%$, respectivamente.

A quantificação da participação do agronegócio no PIB de Minas Gerais pode ser visualizada na Tabela 4, que apresenta, em valores correntes, os valores do PIB de Minas Gerais, nos anos de 1980 e 1996, e fornece a participação percentual do agronegócio em cada ano. De acordo com dados da pesquisa, o agronegócio participou em 1980 com 25\% na composição do PIB total, contra 20\% em 1996.

Tabela 4 - Valor do PIB, do agronegócio e da relação PIB/agronegócio

\begin{tabular}{ccc}
\hline Ano & PIB & Agronegócio \\
\hline $1980^{*}$ & $\mathrm{Cr} \$ 1.180 .560$ & $\mathrm{Cr} \$ 303.335,27$ \\
$1996^{* * *}$ & $\mathrm{R} \$ 78,604$ & $\mathrm{R} \$ 15,091$ \\
\hline
\end{tabular}

Fonte: Resultados da pesquisa. 
Mamadou Diawara,Marília Fernandes Maciel Gomes,

Viviani Silva Lirio \& Marielce de Cássia Ribeiro Tosta

De acordo com os resultados, constata-se que houve queda na participação do agronegócio no PIB do Estado, o qual passou de 25\% em 1980 para $20 \%$ em 1996, o que indica uma variação de 5\% (Tabela 4).

A perda da participação relativa do agronegócio no PIB é fenômeno que vem ocorrendo em muitas economias; isso ocorre à medida que a economia se desenvolve e melhora o PIB per capita. Segundo observações feitas por Montoya e Guilhoto (1999) e Montoya e Finamore (2001), no que se refere às etapas de desenvolvimento, pode-se classificar a economia mineira como uma economia alimentar em vias de industrialização, uma vez que ela detém participação relativa de 25 a $50 \%$ do agronegócio no PIB.

Estudos sobre o agronegócio brasileiros mostraram resultados semelhantes a respeito da relação agronegócio/PIB. Parré (2000) observou que, em 1990, o agronegócio brasileiro respondia por 30,98\% do PIB, valor que caiu para 30,43\% em 1995; para Rodrigues (2000), essa participação passou de 34,97\%, em 1985, para 31,57\%, em 1990, e para 28,91\%, em 1995; para Montoya e Guilhoto (2000), ela reduziu de $32,56 \%$, em 1980, para 28,9\%, em 1995; e para Nunes (2001), ela ficou em 20,6\%, em 1996.

Quando se compara a participação do PIB do agronegócio de Minas Gerais com o do Paraná, estimado por Rodrigues et al. (2001), observase que o valor encontrado para Minas Gerais foi menor que o encontrado pelo citado autor, que estimou o PIB do agronegócio do Paraná em 37,5\% do PIB do Estado.

Apesar de a queda da participação do agronegócio no PIB total ser uma tendência, esse resultado corrobora a dependência do agronegócio mineiro para com alguns produtos primários, como café, soja, laranja e cana-deaçúcar, que apresentam forte participação na composição do PIB do agronegócio e na pauta das exportações do Estado.

Além disso, vale ressaltar a presença de outros complexos industriais dinâmicos, em franca expansão, associados à crescente demanda de 
serviços, fator que também tende a contribuir para redução gradativa da patricipação relativa do agronegócio no PIB.

\section{Conclusão}

Em relação à estrutura produtiva de Minas Gerais nos anos de $1980 \mathrm{e}$ 1996, nota-se queda nas participações do setor agroindustrial no total do Valor Bruto de Produção, do Valor Adicionado, da Demanda Final e das Importações, as quais passaram, respectivamente, de $11,5 \%$ para $8,1 \%$, de $6,9 \%$ para $5,3 \%$, de $13,8 \%$ para $4,0 \%$, e de $10,9 \%$ para $5,5 \%$.

A participação do agronegócio no PIB do Estado passou de $25 \%$, em 1980, para 20\%, em 1996, o que permite classificar a economia mineira como uma economia alimentar em vias de industrialização, no que concerne ao seu desenvolvimento. Além disso, mostrou dependência do agronegócio mineiro para com produtos primários, como café, soja, laranja, cana-de-açúcar, que são muito importantes para a economia do Estado.

A parcela do Agregado I aumentou, de maneira significativa, na constituição do agronegócio estadual, visto que passou de 12,31\%, em 1980, para 20,24\%, em 1996, repetindo a tendência geral do agronegócio brasileiro e de outros Estados. O Agregado II,por sua vez, apresentou queda, de 51,29\%, em 1980, para 43,24\%, em 1996. Por ter sido o setor mais dinâmico na constituição do agronegócio de Minas Gerais, contrariou o comportamento do agronegócio brasileiro e de outros Estados, observado nas pesquisas desenvolvidas no País. O Agregado III permaneceu relativamente estável, de 1980 a 1996, passando de 36,40\% para 36,51\%, o que contraria a tendência de ser o segmento mais dinâmico na geração de renda no agronegócio.

Em face dessas conclusões, torna-se necessário investir em ações que poderiam dar mais valor aos produtos agropecuários, com vistas em aumentar a competitividade do agronegócio como sistema, que vai desde a produção de insumos até o consumidor final, e aproveitar as vantagens 
e potencialidades que o Estado possui em relação aos outros, principalmente a capacidade tecnológica na produção agrícola, a diversidade das diferentes regiões e também a presença de grandes centros de pesquisa e universidades, cuja participação no desenvolvimento agrícola apresenta grandes vantagens. É necessária uma compatibilização entre a produção e a boa estrutura que o Estado possui, para que as cadeias agroindustriais se tornem mais competitivas.

\section{Referências}

BANCO DE DESENVOLVIMENTO DE MINAS GERAIS - BDMG. Economia mineira - 1989; diagnóstico e perspectivas. Belo Horizonte, 1989.

BANCO DE DESENVOLVIMENTO DE MINAS GERAIS - BDMG. Matriz interregional de insumo-produto - Minas Gerais resto do Brasil. Belo Horizonte, 2001.

CURI, W.F. Eficiência e fonte de crecimento da agricultura mineira na dinâmica de ajustamentos da economia brasileira. Viçosa: UFV, 1997. Tese (Doutorado em Economia Rural) - Universidade Federal de Viçosa, 1997.

DAVIS, J.H., GOLBERG. R.A. The concept of agribisiness. Boston: Harvard University, 1957. 135 p.

FINAMORE, E. B., MONTOYA, M. A., Padrões de crescimento do agronegócio brasileiro no período de 1985 a 1995. In: Congresso Brasileiro de Economia e Sociologia Rural, XXXIX, 2001, Recife. Anais Competitividade \& Globalização - Impactos regionais e locais. Recife, SOBER, 2001. CD-ROM.

FUNDAÇÃO JOÃO PINHEIRO - FJP. Perfil de Minas Gerais. Belo Horizonte, 2000. 
FUNDAÇÃO JOÃO PINHEIRO - FJP. Informativo CEI - produto interno bruto 2000. Belo Horizonte, 2001.

FURTUOSO, M. C. O., BARROS, G. S. A. C., GUILHOTO, J. J. M. O Produto Interno Bruto do complexo agroindustrial brasileiro. Revista de Economia e Sociologia Rural, v. 36, n.3, p.9-31, 1998.

FURTUOSO, M.C.O. O produto interno bruto do complexo agroindustrial brasileiro. Piracicaba: ESALQ, 1998. 277 p. Tese (Doutorado em Economia Aplicada) - Escola Superior de Agricultura "Luiz de Queiroz", 1998.

FURTUOSO, M. C. O, GUILHOTO, J. J. M. A estrutura produtiva da economia brasileira e o agronegócio: 1980 a 1995. In: O agronegócio brasileiro no final do século XX: estrutura produtiva, arquitetura organizacional e tendências. Passo Fundo (RS), UPF editora, 2000, cap 12, p.267-306, v.1.

MALASSIS, L. Analyse du complex agro-analimentaire d'apres la comptabilité nacionale française. Economies et Societés, Paris, v. 3, n. 9, p. 1667-1687, 1969.

MONTOYA, M.A., GUILHOTO, J.J.M. Mudança estrutural no agronegócio brasileiro e suas implicações na agricultura familiar. In: TEDESCO, J.C. (Org.). Agricultura familiar: realidades e perspectivas. Passo Fundo: Ediupf, 1999. cap. 5, p. 177-218.

MONTOYA, M.A., GUILHOTO, J.J.M. O agonegócio brasileiro entre 1959 a 1995: dimensão econômica, mudança estrutural e tendências. In: MONTOYA, M.A., PARRÉ, J.L. O agronegócio brasileiro no final do século XX. Passo Fundo: UPF, 2000.

MONTOYA, M.A., FINAMORE, E.B.F. Padrões de crescimento do agronegócio brasileiro entre 1985 a 1995. In: CONGRESSO BRASILEIRO DE ECONOMIA E SOCIOLOGIA RURAL, 39, 2001, Recife. CD-ROM... Brasília: SOBER, 2001. 
Mamadou Diawara,Marília Fernandes Maciel Gomes,

Viviani Silva Lirio \& Marielce de Cássia Ribeiro Tosta

MORETTO, A.C. Relações intersetoriais e interregionais na economia paranaemse. Tese (Doutorado em Economia Aplicada) Universidade de São Paulo - Escola Superior de Agricultura "Luiz de Queiroz", Piracicaba, 2000.

NUNES, E.P. Complexo agroindustrial brasileiro caracterização e dimensionamento. Brasília: Associação Brasileira de Agribusiness (ABAG), 2001. 109 p.

PARRÉ, J.L. O agronegócio nas macroregiões brasileiras: 1985 a 1995. Piracicaba: ESALQ, 2000. Tese (Doutorado em Economia Aplicada) - Escola Superior de Agricultura "Luiz de Queiroz", 2000.

RODRIGUES, R.L. Cooperativas agropecuárias e relações intersetoriais na economia paranaense: uma análise de insumoproduto. Piracicaba: ESALQ, 2000. 175 p. Tese (Doutorado) - Escola Superior de Agricultura “Luiz de Queiroz", 2000.

RODRIGUES, R.L., PARRÉ, J.L., MORETTO, A.C. Dimensionamento e evolução do agronegócio no Paraná. In: CONGRESSO BRASILEIRO DE ECONOMIA E SOCIOLOGIA RURAL, 39, 2001, Recife. CDROM... Brasília: SOBER, 2001.

TOLLINI, H. Velhos e novos mitos sobre agricultura. Revista de Política Agrícola. ano VIII, n.2, ABR./MAI./JUN. 1999, seção II,.p.1-6.

VASCONCELLOS, M.A.S., GREMAUD, A.P.E., TONETO JR., R. Economia brasileira contemporânea. São Paulo: Atlas, 1999. 371 p. 


\begin{abstract}
This study aimed to analyze the economic structure of Minas Gerais State, Brazil, to measure the agribusiness sector of the state in the years of 1980 and 1996 and to evaluate the agribusiness share on total GDP formation, based on inter-regional input-output matrices. The principal results obtained were: a) a significant change in the agribusiness structure occurred from 1980 to 1996; b) the share of aggregate I in total agribusiness increased expressively, rising from $12.31 \%$ in 1980 to $20.24 \%$ in 1996; c) relative stability were observed in the evolution of aggregate III from 1980 to 1996, rising from $36.40 \%$ to $36,51 \%$; d) the aggregate II share declined from $51.29 \%$ in 1980 to $43.25 \%$ in 1996 . The study also shows that aggregate II remains the most important segment of the agribusiness in Minas Gerais State. This indicate that state's economy can be classified as a food economy in a process of industrialization. In relation to its share in GDP, the agribusiness followed the tendency that has been prevalent in Brazil, that is, gradual diminution of its importance in GDP; it decreased of $25 \%$ in 1980 to $20 \%$ in 1996.
\end{abstract}

Keywords: GDP, agribusiness, Minas Gerais. 